\title{
The $\delta{ }^{15} \mathrm{~N}$ value of $\mathrm{N}_{2}$ fixing actinorhizal plants and legumes grown with $\mathrm{N}_{2}$ as the only nitrogen source
}

\author{
Francesco G. Gentili ${ }^{1,2} \cdot$ Kerstin Huss-Danell ${ }^{1}$ \\ Received: 13 December 2018 / Accepted: 24 September 2019 / Published online: 19 November 2019 \\ (C) The Author(s) 2019
}

\begin{abstract}
The aim of this study was to investigate the effects of different plant parts and the age of plants at harvest as well as $\mathrm{N}_{2}$ fixing bacterial strains on the $\mathrm{N}$ concentration in symbiotic plant parts, especially on the $\delta^{15} \mathrm{~N}$ signature of the actinorhizal plants and legumes. The ${ }^{15} \mathrm{~N}$ natural abundance method was used. Two actinorhizal plants were studied: Alnus incana (L.) infected with the Frankia strains ArI3 or "lsF" (local source of Frankia) and Hippophaë rhamnoides (L.) infected with the Frankia strains T1 or E15b. Two legume species were studied: Hedysarum coronarium (L.), infected with a soil suspension, and Robinia pseudoacacia (L.), infected with a crushed nodule suspension. It was particularly interesting that in A. incana, the two Frankia strains affected not only $\mathrm{N}$ concentration and $\delta^{15} \mathrm{~N}$ signature of leaves and roots, but also had an impact on plant growth at first harvest. In Hippophaë rhamnoides plants inoculated with the Frankia strains T1 and E15b, N concentrations and $\delta^{15} \mathrm{~N}$ values did not differ at any harvest time. However, plants nodulated by the Frankia strain T1 showed a higher nitrogen fixation rate and higher plant dry matter at all harvesting times. Based on our results for the quantification of $\mathrm{N}_{2}$ fixation with the "B" value, that is the $\delta^{15} \mathrm{~N}$ value of the $\mathrm{N}_{2}$ fixing plants relying only on $\mathrm{N}_{2}$ fixation, plant parts, ages and strains should be carefully considered.
\end{abstract}

Keywords Actinorhizal plants $\cdot \mathrm{B}$ value $\cdot$ Leguminous plant $\cdot{ }^{15} \mathrm{~N}$ natural abundance $\cdot \delta^{15} \mathrm{~N} \cdot \mathrm{N}_{2}$ fixation

\section{Introduction}

The ${ }^{15} \mathrm{~N}$ natural abundance (NA) method is an important technique to measure $\mathrm{N}_{2}$ fixation, $\mathrm{N}$ uptake and $\mathrm{N}$ transfer in the soil-plant system. This method is used in plant physiology and ecology (Handley and Raven 1992; Högberg 1997; Robinson 2001), but it can also be applied at the farm level as well as at the landscape level (Unkovich and Pate 2000). The ${ }^{15} \mathrm{~N}$ NA method has become more commonly used to quantify $\mathrm{N}_{2}$ fixation (Okito et al. 2004).

However, to adequately and correctly quantify $\mathrm{N}_{2}$ fixation, we need to know the $\delta^{15} \mathrm{~N}$ of soil $\mathrm{N}$; if a legume or actinorhizal plant was totally reliant on soil mineral and organic $\mathrm{N}$, its $\delta^{15} \mathrm{~N}$ should resemble that of the soil mineral $\mathrm{N}$ taken up (Unkovich et al. 2008). Hence, the $\delta^{15} \mathrm{~N}$ of a legume or actinorhizal plant

Francesco G. Gentili

francesco.gentili@slu.se

1 Department of Agricultural Research for Northern Sweden, Umeå, Sweden

2 Department of Forest Biomaterials and Technology, Swedish University of Agricultural Sciences (SLU), SE-901

83 Umeå, Sweden using a combination of atmospheric $\mathrm{N}_{2}$, soil mineral and organic $\mathrm{N}$ for growth should range between the values of the two possible $\mathrm{N}$ sources: soil and atmospheric $\mathrm{N}_{2}$ (Andrews et al. 2011). Usually, to calculate the \% Ndfa (percentage of $\mathrm{N}$ derived from the atmospheric $\mathrm{N}_{2}$ ), non- $\mathrm{N}_{2}$-fixing 'reference' plants are used to obtain the $\delta^{15} \mathrm{~N}$ of soil mineral and organic $\mathrm{N}$ and the $\mathrm{N}_{2}$ fixation by the legume or actinorhizal plant can be calculated using the following formula (Eq. 1):

$\% \mathrm{Ndfa}=\left(\frac{\delta^{15} \mathrm{~N} \text { of referenceplant }-\delta^{15} \mathrm{~N} \text { of } \mathrm{N}_{2} \text { fixingplant }}{\delta^{15} \mathrm{~N} \text { of reference plant }-\delta^{15} \mathrm{~N} \text { of } \mathrm{N}_{2}}\right) \times 100$

In ${ }^{15} \mathrm{~N}$ enrichment studies, isotopic discrimination during $\mathrm{N}_{2}$ fixation is generally considered to be zero; however, isotopic discrimination should be considered when using ${ }^{15} \mathrm{~N}$ natural abundance (Unkovich et al. 2008). The natural abundance of atmospheric $\mathrm{N}_{2}$ will have a $\delta^{15} \mathrm{~N}$ of $0 \%$, by definition. The above equation assumes that $\mathrm{N}_{2}$ fixing plants relying only on $\mathrm{N}_{2}$ fixation do not have any isotope discrimination, hence they have a $\delta^{15} \mathrm{~N}$ similar to the $\delta^{15} \mathrm{~N}$ of atmospheric $\mathrm{N}_{2}$. However, $\mathrm{N}_{2}$ fixing plants have a certain discrimination between ${ }^{14} \mathrm{~N}$ and ${ }^{15} \mathrm{~N}$, even when relying only on $\mathrm{N}_{2}$ fixation. Hence, to correctly quantify $\mathrm{N}_{2}$ fixation, the ${ }^{15} \mathrm{~N}$ NA method 
demands a constant, namely the " $\mathrm{B}$ " value, which is the $\delta^{15} \mathrm{~N}$ value of the $\mathrm{N}_{2}$ fixing plants relying only on $\mathrm{N}_{2}$ fixation. Therefore, the above Eq. 1, including the $\mathrm{B}$ value, can be written as follows (Eq. 2):

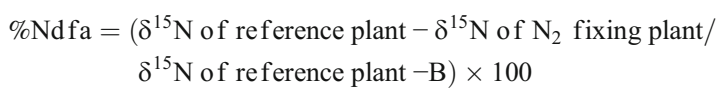

The use of the equation including the $\mathrm{B}$ value will result in a more accurate $\mathrm{N}_{2}$ fixation contribution and hence a more precise calculation of the percentage of $\mathrm{N}$ derived from the atmosphere. Several studies have emphasised the importance of measuring B values (Kurdali 2009; Andrews et al. 2011; Chalk et al. 2016). Previous studies on legumes have shown that the B value can vary with plant species and age (Carlsson et al. 2006; Unkovich et al. 1993), bacterial strains, and growing conditions (Carlsson et al. 2006; Ledgard 1989; Unkovich and Pate 2000). Much less is known about actinorhizal plants; however, Domenach et al. (1989) have investigated $\delta^{15} \mathrm{~N}$ in Alnus incana and A. glutinosa inoculated with four different Frankia strains. Tjepkema et al. (2000) studied differences in $\delta^{15} \mathrm{~N}$ values among parts of the actinorhizal plants Alnus glutinosa (L.) Gaertn., Casuarina cunninghamiana Miq., Datisca glomerata (Presl.) Baill. and Myrica gale L grown with $\mathrm{N}$-free solution. However, plants were inoculated mainly with crushed nodule suspensions without testing different strains (Tjepkema et al. 2000).

The group of actinorhizal plants includes eight families of mainly woody plants that are infected with $\mathrm{N}_{2}$-fixing actinomycetes of the genus Frankia (Huss-Danell 1997). In the present work, we studied the actinorhizal plants Alnus incana L. Moench (grey alder) and Hippophaë rhamnoides L. (sea buckthorn). H. rhamnoides is a multipurpose plant that has been exploited in East Europe and Asia for several years ( $\mathrm{Li}$ and Schroeder 1996; Zielinska and Nowak 2017). Alnus incana is a fast-growing tree that thrives in alluvial nutrientpoor soils, and it is used to stabilize damaged forest topsoils (Flores Fernández et al. 2019). These two actinorhizal plants have the following different Frankia infection pathways: via root hairs in A. incana and via intercellular penetration in H. rhamnoides (Berry and Torrey 1979; Gentili et al. 2006). Generally, each of actinorhizal plant species has a different infection pathway (Pawlowski et al. 2011), and is infected by a specific Frankia strain; however some Frankia strains such as UFI 132715 are able to form nodules in actinorhizal plant species having different infections pathways (Lumini and Bosco 1996).

The legumes studied in the present work were Hedysarum coronarium (Italian "sainfoin" or "sulla") infected by Rhizobium sullae (de Diego-Diaz et al. 2018) and Robinia pseudoacacia (black locust) infected by Mesorhizobium and Rhizobium (Andrews and Andrews 2017). Hedysarum coronarium is a good forage plant for Mediterranean regions, and it can grow in arid environments and clay soils (Chisci et al. 2001), while $R$. pseudoacacia is a widespread tree used in agroforestry and land reclamation (Groninger et al. 1997).

The main aim of this work was to determine the $B$ values in the four plant species mentioned above at different plant ages and with different Frankia strains for the actinorhizal plants and with crushed nodule or soil suspension for the legumes.

\section{Materials and methods}

\subsection{Plant cultivation}

Alnus incana seeds were obtained from a clone (Huss-Danell 1991), while H. rhamnoides from Hungary and R. pseudoacacia from Poland were purchased from Sandeman Seeds (UK). Hedysarum coronarium seeds were collected in central Italy (Santa Sofia, Forlì, Italy). Seeds of $H$. rhamnoides and $R$. pseudoacacia were surface-sterilised as previously described by Gentili and Huss-Danell (2002). Alnus incana seeds were washed in water containing a few drops of detergent, immersed in hydrogen peroxide $(30 \% \mathrm{v} / \mathrm{v})$ for $1 \mathrm{~h}$, shaken a few times manually, and then carefully rinsed with sterile water. Hedysarum coronarium seeds were not surfacesterilised. Hippophaë rhamnoides and R. pseudoacacia were sown in Petri dishes containing perlite, He. coronarium was sown in $8 \times 8 \mathrm{~cm}$ plastic pots containing perlite and A. incana was sown in Magenta jars (Sigma, St Louis, Mo, USA) containing glass beads. All seeds were watered with modified Nfree Evans solution (Huss-Danell 1978) diluted to 1/10 of full strength. The perlite, glass beads and nutrient solution were sterile. The seedlings were transferred to larger pots twice for the legumes He. coronarium and R. pseudoacacia or three times for A. incana and H. rhamnoides (Table 1).

During the entire experiment, plants were watered with $\mathrm{N}$ free Evans solution diluted to $1 / 10$ of full strength. During the whole growth period (end of February to beginning of October), the plants were kept in a greenhouse in Umeå, Sweden $\left(63^{\circ} 45^{\prime} \mathrm{N}\right)$, with $17 \mathrm{~h}$ of supplemental light set to about $25{ }^{\circ} \mathrm{C}$ and $7 \mathrm{~h}$ of darkness set to about $15{ }^{\circ} \mathrm{C}$. Philips HPI/T $400 \mathrm{~W}$ lamps were used. Relative air humidity was set to $40 \%$.

\subsection{Inoculation and harvest of plants}

Some of the A. incana seedlings were inoculated with the Frankia strain ArI3 (Berry and Torrey 1979) grown on P + $\mathrm{N}$ medium (Van Ghelue et al. 1997). The Frankia cells were collected by centrifugation at $7000 \mathrm{~g}$ for $10 \mathrm{~min}$ at $22^{\circ} \mathrm{C}$, and the supernatant was discarded. The cell pellet was washed twice by centrifugation (as above-mentioned), using $\mathrm{N}$-free Evans solution diluted to 1/10 of full strength. Each seedling was inoculated with approximately $6 \mathrm{mg}$ (wet weight) of Frankia cells added into the Magenta jars. Another part of 
Table 1 Plants age at different experimental phases. WAS stands for weeks after sowing

\begin{tabular}{lllll}
\hline Plant & Inoculation WAS & Transfer WAS & Harvest WAS & Harvest number \\
\hline A. incana & 2 & 4 to $6 \times 6 \mathrm{~cm}$ pot & & \\
& & 11 to $10 \times 10 \mathrm{~cm}$ pot & 18.5 & 1 \\
& & 19 to $11 \times 11 \times 12 \mathrm{~cm}$ pot & 32 & 2 \\
He. coronarium & 2 & 1.5 to $10 \times 10 \mathrm{~cm}$ pot & 14 & 1 \\
& & 10.5 to $11 \times 11 \times 12 \mathrm{~cm}$ pot & 23 & 2 \\
H. rhamnoides & 3.5 & 3 to $6 \times 6 \mathrm{~cm}$ pot & & 1 \\
& 8 & 6 to $8 \times 8 \mathrm{~cm}$ pot & 18 & 2 \\
R. pseudoacacia & 3.5 & 19 to $11 \times 11 \times 12 \mathrm{~cm}$ pot & 31 & 1 \\
& & 2 to $8 \times 8 \mathrm{~cm}$ pot & 12.5 & 2 \\
\hline
\end{tabular}

the A. incana seedlings was inoculated with the crushed root nodule suspension from A. incana, the local source of Frankia (lsF) (Huss-Danell 1991).

Hippophae rhamnoides seedlings were inoculated with the strains E15b (Lumini and Bosco 1996) and T1 (Chaia 1998), both of which were grown in K-medium with casein hydrolysate and yeast extract as N source (Lumini et al. 1996). Both strains were harvested as described above for the Frankia strain, ArI3. However, each H. rhamnoides seedling was inoculated with $30 \mathrm{mg}$ (wet weight) of Frankia cells the first time and $16 \mathrm{mg}$ of cells the second time (Table 1).

Hedysarum coronarium was inoculated with a soil suspension from an Italian area where this legume grows naturally, while $R$. pseudoacacia was inoculated with a crushed root nodule suspension from plants of $R$. pseudoacacia growing in an Italian nursery garden. For inoculation times, see Table 1. All plant species were harvested twice at the different plant ages indicated in Table 1. Once harvested, the plants were immediately dried at $60{ }^{\circ} \mathrm{C}$ for $48 \mathrm{~h}$ at the first harvest time and for $72 \mathrm{~h}$ at the second harvest time. This difference between the drying times was because at the second harvest, plants were much larger and more lignified. The dried shoots and the dried roots, including the nodules, were milled and analysed for $\mathrm{N}$ and ${ }^{15} \mathrm{~N}$ as previously described (Gentili 2006). All seeds were dried at $60^{\circ} \mathrm{C}$ for $24 \mathrm{~h}$, milled and analysed as above-mentioned.

\subsection{Nitrogenase activity}

Acetylene-reducing activity (ARA) was measured in five randomly chosen $H$. rhamnoides plants for the two Frankia strains at 21.5 weeks after sowing. The measurements were done three times a week, with one day in between measurements. Each intact individual plant was placed in a gastight chamber (HussDanell 1978) during exposure to $10 \%(v / v) \mathrm{C}_{2} \mathrm{H}_{2}$ in air. During these incubations, the plants were kept in the greenhouse. The formation of $\mathrm{C}_{2} \mathrm{H}_{4}$ was measured by gas chromatography as described previously (Valverde et al. 2000).

\subsection{Statistical method}

One-way ANOVA was used to identify statistically significant differences. Statistical calculations were performed using the software package Minitab (Minitab Inc., State College Pennsylvania, PA, USA, 2000), with $P<0.05$ as the significance level.

\section{Results}

The legume seeds had a higher nitrogen concentration than the actinorhizal seeds (Table 2). Only Robinia pseudoacacia seeds had a positive $\delta^{15} \mathrm{~N}$ value when compared to the other seeds analysed (Table 2). However, regarding the weight of a single seed in comparison with the plant dry matter and leaf plus root dry matter (Tables 2 and 3), the influence of the $\mathrm{N}$ and $\delta^{15} \mathrm{~N}$ of the seeds had a negligible impact on the $\mathrm{N}$ and $\delta^{15} \mathrm{~N}$ of the plants. There was a great difference in $\mathrm{N}$ concentration among the plants analysed, ranging from $0.94 \%$ in roots of Alnus incana to $3.39 \%$ in leaves of Hippophae rhamnoides. However, these differences were not only due to differences in plant species, but also there were significant differences among plant parts, time of harvest
Table 2 Dry seeds mass, nitrogen concentration (\% of seed dry mass) and $\delta^{15} \mathrm{~N}$ values in dry seeds of the studied plant species. The $\mathrm{N}$ and $\delta^{15} \mathrm{~N}$ values are the mean \pm SE of 5 replicates

\begin{tabular}{llll}
\hline Plant & Dry weight of 100 seeds $(\mathrm{g})$ & $\mathrm{N} \%$ & $\delta^{15} \mathrm{~N}$ \\
\hline A. incana & 0.05 & $3.26 \pm 0.04$ & $-0.35 \pm 0.09$ \\
H. rhamnoides & 0.89 & $4.1 \pm 0.1$ & $-0.24 \pm 0.04$ \\
He. coronarium & 0.46 & $7.72 \pm 0.11$ & $-0.33 \pm 0.13$ \\
R. pseudoacacia & 2 & $6.6 \pm 0.08$ & $4.22 \pm 0.02$ \\
\hline
\end{tabular}


Table 3 Plant dry matter (g) and leaf+root (g) of the two actinorhizal plant species inoculated with two different Frankia strains and of the two leguminous plants inoculated. All the plants were harvested at two different time. Values are the mean $\pm \mathrm{SE}$ of 5 replicates. na stands for not available

\begin{tabular}{|c|c|c|c|c|}
\hline Plant & Plant DM (g) 1st harvest & Plant DM (g) 2nd harvest & Leaf+root DM (g) 1st harvest & $\begin{array}{l}\text { Leaf+root DM (g) } \\
\text { 2nd harvest }\end{array}$ \\
\hline A. incana $x$ ArI3 & & & $2.46 \pm 0.4$ & $13.34 \pm 1.47$ \\
\hline A. incana $x \mathrm{lsF}$ & & & $1.73 \pm 0.18$ & $13.02 \pm 1.81$ \\
\hline H. rhamnoides $x \mathrm{E} 15 \mathrm{~b}$ & $2.2 \pm 0.27$ & $10.49 \pm 0.24$ & & \\
\hline H. rhamnoides $x \mathrm{~T} 1$ & $3.21 \pm 0.14$ & $17.59 \pm 1.41$ & & \\
\hline He. coronarium & na & $10.08 \pm 0.46$ & & \\
\hline R. pseudoacacia & & & $1.97 \pm 0.29$ & $24.31 \pm 2.98$ \\
\hline
\end{tabular}

and Frankia strains (Table 4). In particular, A. incana inoculated with Frankia strain ArI3 had a significantly higher N concentration in both leaves and roots at first harvest than at second harvest (Table 4). However, A. incana inoculated with Frankia strain lsF had a significantly higher $\mathrm{N}$ concentration in leaves at second harvest than at first harvest (Table 4).

In $H$. rhamnoides, there were no effects on $\mathrm{N}$ concentration due to harvest time or strains used (Table 4). Even in Hedysarum coronarium, harvest time had no effect on leaf $\mathrm{N}$ concentrations (Table 4). However, in R. pseudoacacia, roots had higher $\mathrm{N}$ concentrations than leaves at both harvest times, while harvest time did not have any clear effect on $\mathrm{N}$ concentrations (Table 4).

The $\delta^{15} \mathrm{~N}$ values of the $\mathrm{N}_{2}$ fixing plants relying only on $\mathrm{N}_{2}$ fixation or $\mathrm{B}$ values are shown in Table 5. The $\delta^{15} \mathrm{~N}$ ranged from -2.62 in leaves of $A$. incana inoculated with the "lsF" to 0.77 in roots of $R$. pseudoacacia (Table 5). The $\delta^{15} \mathrm{~N}$ was negative in the two actinorhizal plants studied with all the Frankia strains, while the two legume species studied showed negative (He. coronarium) and both negative and positive $\delta{ }^{15} \mathrm{~N}$ (R. pseudoacacia). On the one hand, in A. incana inoculated with the ArI3 strain, the only relevant difference among plant parts and time of harvest was a slight, but significantly more negative, $\delta^{15} \mathrm{~N}$ value in the roots at the second harvest (Table 5). On the other hand, A. incana inoculated with the "lsF" did not show any relevant differences among plant parts and times of harvest (Table 5). Hippophaë rhamnoides was even more interesting because, although the two strains did not affect $\mathrm{N}$ concentrations and $\delta{ }^{15} \mathrm{~N}$ signatures among plant parts and time of harvest, they greatly affected plant biomass (compare Tables 3, 4 and 5) and acetylene-reducing activity (Fig. 1). Under these experimental conditions, the strain T1 fixed $\mathrm{N}_{2}$ much more efficiently than the strain E15b.

Interestingly, in $H$. rhamnoides, there were clear differences in $\delta^{15} \mathrm{~N}$ values due to the time of harvest and the plant parts; roots had a more negative $\delta^{15} \mathrm{~N}$ than leaves. However, Frankia strains did not significantly affect the $\delta^{15} \mathrm{~N}$ signature of $H$. rhamnoides (Table 5).

$H e$. coronarium showed a significant difference between $\delta$ ${ }^{15} \mathrm{~N}$ values of leaves at different harvesting times and between leaves and roots (Table 5). In He. coronarium, $\mathrm{N}$ concentrations and $\delta{ }^{15} \mathrm{~N}$ values had a different trend (compare Tables 4 and 5).

$R$. pseudoacacia $\delta{ }^{15} \mathrm{~N}$ signatures followed a trend similar to that of $\mathrm{N}$ concentrations (Tables 4 and 5). In this leguminous species, roots had $\delta{ }^{15} \mathrm{~N}$ signatures higher than leaves at both harvesting times, while harvesting time did not have any clear effect on $\mathrm{N}$ concentrations (Table 4).

\section{Discussion}

It is particularly interesting that in A. incana, the two Frankia strains affected not only $\mathrm{N}$ concentration and $\delta^{15} \mathrm{~N}$ signatures

Table 4 Nitrogen concentration in leaves and in roots with nodules at different harvest time and with different Frankia strains

\begin{tabular}{llllll}
\hline Plant & Inoculum & Leaf N\% First harvest & Leaf N\% Second harvest & Root N\% First harvest & Root N\% Second harvest \\
\hline A. incana & ArI3 & $2.1 \pm 0.3 \mathbf{a A}$ & $1.15 \pm 0.05 \mathbf{b A}$ & $1.42 \pm 0.05 \mathbf{a A}$ & $0.94 \pm 0.03 \mathbf{c A}$ \\
& ls $F$ & $1.24 \pm 0.07 \mathbf{a B}$ & $1.78 \pm 0.05 \mathbf{b B}$ & $1.34 \pm 0.04 \mathbf{a A}$ & $1.27 \pm 0.03 \mathbf{~ a B}$ \\
H. rhamnoides & E15b & $3.24 \pm 0.09 \mathbf{a A}$ & $3.21 \pm 0.14 \mathbf{a A}$ & $3.02 \pm 0.24 \mathbf{a A}$ & $2.75 \pm 0.14 \mathbf{a A}$ \\
& T1 & $3.39 \pm 0.16 \mathbf{a A}$ & $3.12 \pm 0.15 \mathbf{a A}$ & $3.27 \pm 0.19 \mathbf{a A}$ & $2.96 \pm 0.14 \mathbf{a A}$ \\
He. coronarium & Soil suspension & $2.18 \pm 0.11 \mathbf{a}$ & $1.96 \pm 0.06 \mathbf{a}$ & na & $2.06 \pm 0.17 \mathbf{a}$ \\
R. pseudoacacia & Crushed nodules & $2.17 \pm 0.34 \mathbf{a}$ & $2.27 \pm 0.1 \mathbf{a}$ & $2.88 \pm 0.2 \mathbf{b}$ & $2.71 \pm 0.09 \mathbf{b}$ \\
\hline
\end{tabular}

Different letters mean differences at $\mathrm{p} \leq 0.05$ as significance level. Lower case letters represent differences between values of different columns but of the same line. Upper case letters represent differences between Frankia strains infecting the same actinorhizal species and compared values of different lines but of the same column. Values are the mean $\pm \mathrm{SE}$ of 5 replicates. na stands for not available 
Table $5 \quad \delta^{15} \mathrm{~N}$ values (B values) of leaves and roots at different harvest times and in plants with different Frankia strains

\begin{tabular}{llllll}
\hline Plant & Frankia strain & Leaf $\delta{ }^{15} \mathrm{~N}$ First harvest & Leaf $\delta^{15} \mathrm{~N}$ Second harvest & Root $\delta^{15} \mathrm{~N}$ First harvest & Root $\delta^{15} \mathrm{~N}$ Second harvest \\
\hline A. incana & Arl3 & $-2.18 \pm 0.11 \mathbf{a A}$ & $-2.14 \pm 0.05 \mathbf{a A}$ & $-2.08 \pm 0.1 \mathbf{a A}$ & $-2.43 \pm 0.06 \mathbf{b A}$ \\
& ls $F$ & $-2.54 \pm 0.05 \mathbf{~ a B}$ & $-2.62 \pm 0.04 \mathbf{a B}$ & $-2.41 \pm 0.08 \mathbf{a B}$ & $-2.43 \pm 0.12 \mathbf{~ a A}$ \\
H. rhamnoides & E15b & $-1.75 \pm 0.04 \mathbf{~ a A}$ & $-1.28 \pm 0.06 \mathbf{b A}$ & $-2.22 \pm 0.12 \mathbf{c A}$ & $-2.57 \pm 0.2 \mathbf{c A}$ \\
& T1 & $-1.70 \pm 0.07 \mathbf{~ a A}$ & $-1.04 \pm 0.11 \mathbf{b A}$ & $-2.49 \pm 0.06 \mathbf{c A}$ & $-2.40 \pm 0.06 \mathbf{c A}$ \\
He. coronarium & Soil suspension & $-0.49 \pm 0,09 \mathbf{a}$ & $-1.31 \pm 0.26 \mathbf{b}$ & na & $-0.54 \pm 0.1 \mathbf{a c}$ \\
R. pseudoacacia & Crushed nodule & $-1.31 \pm 0.16 \mathbf{a}$ & $-1 \pm 0.12 \mathbf{a}$ & $0.77 \pm 0.39 \mathbf{b}$ & $0.03 \pm 0.21 \mathbf{b}$ \\
\hline
\end{tabular}

Different letters mean differences at $\mathrm{p} \leq 0.05$ as significance level. Lower case letters represent differences between values of different columns but belonging to the same line. Upper case letters represent differences between Frankia strains infecting the same actinorhizal species and compared values of different lines but of the same column. Values are the mean $\pm \mathrm{SE}$ of 5 replicates. na stands for not available

of leaves and roots, but also had an impact on plant growth at first harvest (compare Tables 3, 4 and 5). This could be due to a faster root colonisation and nodule formation by the strain ArI3 compared to the lsF. At the second harvest, the plants inoculated with the lsF had similar dry matter values compared to the plants inoculated with the ArI3 strain (Table 3) and a higher nitrogen concentration in both leaves and roots (Table 4). This could be due to a higher $\mathrm{N}_{2}$ fixation of the plants inoculated with $1 \mathrm{sF}$ than plants inoculated with ArI3. Remarkably, plants infected with the $1 \mathrm{sF}$ strain had the $\delta^{15} \mathrm{~N}$ value of the leaves at second harvest about $0.5 \delta$ units more negative than plants inoculated with the ArI3 Frankia strain. A previous study had shown that the choice of the Rhizobium strain significantly influenced the B values in shoots of Trifolium hybridum and Trifolium repens and the N contents

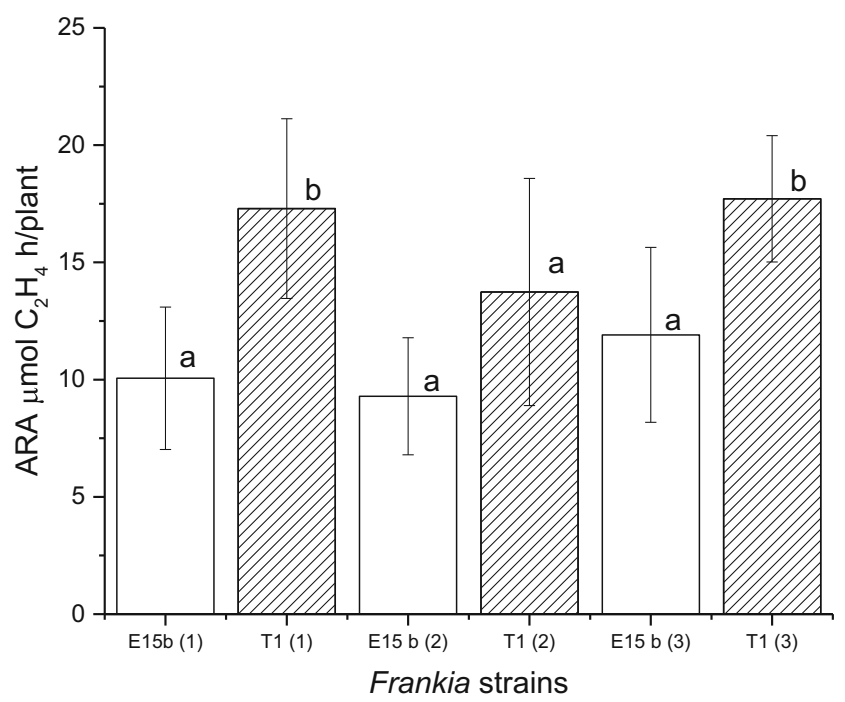

Fig. 1 Acetylene reducing activity in five randomly chosen $H$. rhamnoides plants measured at three different date during one week. Empty bars show ARA for plants infected by the Frankia strain E15 b while bars with grid show ARA for plants infected by the T1 Frankia strain. Bars stand for mean \pm SD of five replicates. Different letters on the top of the bars represent statistically differences among plants infected by different strains at the same measurement date at $p \leq 0.05$ as significance level in all Trifolium species tested (Carlsson et al. 2006). Furthermore, in legumes, considerable variation was found in $\delta^{15} \mathrm{~N}$ values of plant herbage $(-4.5$ to +0.8$)$; the extent of isotopic discrimination was dependent on both the host plant and the infecting rhizobial strain (Steele et al. 1983). In a previous study, A. incana had a leaf $\delta^{15} \mathrm{~N}$ of approximately -1.4 , hence less negative than in the present study. However, the inoculating strain and the age of the plants were not specified (Domenach et al. 1989). Working on actinorhizal plants, Tjepkema et al. (2000) found that whole plant $\delta^{15} \mathrm{~N}$ for the four actinorhizal plants examined ranged from -1.41 to $-1.90 \%$. However, they harvested the plants when they reached a dry mass of between 0.5 and $4 \mathrm{~g}$, which was similar to our results from the first harvest, but significantly smaller than our results from the second harvest, where actinorhizal plant dry matter values ranged from 10.5 to $17.6 \mathrm{~g}$.

Hippophaë rhamnoides plants inoculated with the T1 Frankia strain showed a greater biomass and higher ARA than plants inoculated with the E15b strain (Table 3, Fig. 1). Consequently, under these experimental conditions, the $\mathrm{T} 1$ strain had a significantly higher efficiency to fix $\mathrm{N}_{2}$ than the E15b strain. However, for both $\mathrm{N}$ concentrations and $\delta^{15} \mathrm{~N}$ values, plants infected with the E15b and T1 strain, respectively, did not differ at any harvest time (Tables 4 and 5). This means that although $\mathrm{T} 1$ fixed $\mathrm{N}_{2}$ more efficiently than E15b, as also confirmed by the ARA measurements (Fig. 1), which resulted in larger plants at both harvesting times, it had the same ${ }^{15} \mathrm{~N}$ discrimination as the less productive E15b. On the one hand, concerning $\mathrm{N}$ concentrations in $H$. rhamnoides, there was no significant difference among Frankia strains, time of harvest and plant parts. On the other hand, in terms of $\delta^{15} \mathrm{~N}$, there were differences at time of harvest in leaves and among plant parts, with more negative values for nodulated roots than for leaves. The fact that leaves showed differences over time is extremely relevant, because leaves are generally used to measure $\mathrm{N}_{2}$ fixation for both actinorhizal plants and legumes. Hence, it would be important in future studies to follow $\delta^{15} \mathrm{~N}$ values of actinorhizal and legume woody plants grown with $\mathrm{N}_{2}$ as the only nitrogen source during several growing seasons. 
In the present study, leguminous plants showed a higher $\delta^{15} \mathrm{~N}$ of roots compared to leaves, as had been previously shown (Unkovich et al. 2008). In contrast, the two actinorhizal plants inoculated with four different Frankia strains generally had more negative $\delta^{15} \mathrm{~N}$ values of nodulated roots than leaves (Table 5). It seems that actinorhizal plants have a great variability of ${ }^{15} \mathrm{~N}$ fractionation among plant parts, as had also been shown by Tjepkema et al. (2000), where some plants grown on $\mathrm{N}_{2}$-free medium had more positive $\delta^{15} \mathrm{~N}$ values for roots than for leaves, while the opposite was true for other actinorhizal plant species.

In conclusion, for the calculation of the $\% \mathrm{Ndfa}$, the $\delta^{15} \mathrm{~N}$ value of $\mathrm{N}_{2}$ fixing plants relying only on $\mathrm{N}_{2}$ as nitrogen source (B value, see above Eq. 2) should be used instead of the $\delta^{15} \mathrm{~N}$ value of atmospheric $\mathrm{N}_{2}$. This will produce more accurate estimations of $\% \mathrm{Ndfa}$. In fact, the use of $\delta^{15} \mathrm{~N}$ of atmospheric $\mathrm{N}_{2}(0 \%)$ as the B value could result in an underestimation or overestimation of the \% Ndfa if the real $\mathrm{B}$ value is positive or negative, respectively. Based on our results, the use of the B value of different plant parts, plant age and infecting strains should be carefully considered.

Acknowledgements Open access funding provided by Swedish University of Agricultural Sciences. We thank Anna Maria Ericsson and Håkan Wallmark for valuable technical help. We greatly appreciate the financial support by the Swedish Council for Forestry and Agricultural Research and EC FAIRBM- 972009.

Open Access This article is distributed under the terms of the Creative Commons Attribution 4.0 International License (http:// creativecommons.org/licenses/by/4.0/), which permits unrestricted use, distribution, and reproduction in any medium, provided you give appropriate credit to the original author(s) and the source, provide a link to the Creative Commons license, and indicate if changes were made.

\section{References}

Andrews M, Andrews ME (2017) Specificity in legume-rhizobia symbioses. Int J Mol Sci 18:705. https://doi.org/10.3390/ijms18040705

Andrews M, James EK, Sprent JI, Boddey RM, Gross E, do Reis Jr FB (2011) Nitrogen fixation in legumes and actinorhizal plants in natural ecosystems: values obtained using ${ }^{15} \mathrm{~N}$ natural abundance. Plant Ecol \& Diversity 4: 131-140

Berry AM, Torrey JG (1979) Isolation and characterization in vivo and in vitro of an actinomycetous endophyte from Alnus rubra bong. Symbiotic nitrogen fixation and the management of temperate forests. Edited by Gordon JC, Wheeler CT and Perry DA. Oregon State University, Corvallis, OR, In

Carlsson G, Palmborg C, Huss-Danell K (2006) Discrimination against ${ }^{15} \mathrm{~N}$ in three $\mathrm{N}_{2}$-fixing Trifolium species as influenced by Rhizobium strain and plant age. Acta Agriculturae Scandinavica, Section B-Soil \& Plant Sci 56:31-38

Chaia E (1998) Isolation of an effective strain of Frankia from nodules of Discaria trinervis (Rhamnaceae). Plant Soil 205:99-102

Chalk PM, Inácio CT, Balieiro FC, Rouws JRC (2016) Do techniques based on ${ }^{15} \mathrm{~N}$ enrichment and ${ }^{15} \mathrm{~N}$ natural abundance give consistent estimates of the symbiotic dependence of $\mathrm{N}_{2}$ fixing plants? Plant Soil 399:415-426
Chisci GC, Bazzoffi P, Pagliai M, Papini R, Pellegrini S, Vignozzi N (2001) Association of sulla and atriplex shrub for the physical improvement of clay soils and environmental protection in Central Italy. Agric Ecosyst and Environ 84:45-53

de Diego-Diaz B, Treu L, Campanaro S, da Silva Duarte V, Basaglia M, Favaro L, Casella S, Squartini A (2018) Genome sequence of Rhizobium sullae HCNT1 isolated from Hedysarum coronarium nodules and featuring peculiar denitrification phenotypes. Genome Announc 6:e01518-e01517

Domenach AM, Kurdali F, Bardin R (1989) Estimation of symbiotic dinitrogen fixation in alder forest by the method based on natural ${ }^{15} \mathrm{~N}$ abundance. Plant Soil 118:51-59

Flores Fernández JL, Hartmann P, von Wilpert K (2019) Planting of alder trees at the edge of skid trails helps to stabilize forest topsoil structure against damage caused by heavy forestry machines. Soil and Tillage Res 187:214-218

Gentili F, Huss-Danell K (2002) Phosphorus modifies the effects of nitrogen on nodulation in split-root systems of Hippophaë rhamnoides. New Phytol 153:53-61

Gentili F (2006) Phosphorus, nitrogen and their interactions affect $\mathrm{N}_{2}$ fixation. $\mathrm{N}$ isotope fractionation and $\mathrm{N}$ partitioning in Hippophaë rhamnoides, Symbiosis 41:39-45

Gentili F, Wall LG, Huss-Danell K (2006) Effects of phosphorus and nitrogen on nodulation are seen already at the stage of early cortical cell divisions in Alnus incana. Ann of Bot 98:309-315

Groninger JW, Zedaker SM, Fredericksen TS (1997) Stand characteristics of intercropped loblolly pine and black locust. For Ecol and Manag 91:221-227

Handley LL, Raven JA (1992) The Use of natural abundance of nitrogen isotopes in plant physiology and ecology. Plant Cell Environ 15: 965-985.

Högberg P (1997) ${ }^{15} \mathrm{~N}$ natural abundance in soil-plant systems. Tansley review no. 95. New Phytol 137:179-203

Huss-Danell K (1978) Nitrogenase activity measurements in intact plants of Alnus incana. Physiol Plant 43:372-376

Huss-Danell K (1997) Actinorhizal symbioses and their $\mathrm{N}_{2}$ fixation. Tansley review no. 93. New Phytol 136:375-405

Huss-Danell K (1991) Influence of host (Alnus and Myrica) genotype on infectivity, $\mathrm{N}_{2}$ fixation, spore formation, and hydrogenase activity in Frankia. New Phytol 119:121-127

Kurdali F, Al-Shamma'a (2009) Natural abundance of ${ }^{15} \mathrm{~N}$ and ${ }^{13} \mathrm{C}$ in leaves of some $\mathrm{N}_{2}$-fixing and non- $\mathrm{N}_{2}$-fixing trees and shrubs in Syria. Isotopes in Environ and Health Stud 45: 198-207

Ledgard SF (1989) Nutrition, moisture and Rhizobial strain influence isotopic fractionation during $\mathrm{N}_{2}$ fixation in pasture legumes. Soil Biol and Biochem 21:65-68

Li TSC, Schroeder WR (1996) Sea buckthorn (Hippophae rhamnoides): a multipurpose plant. HortTechnol 6:370-380

Lumini E, Bosco M (1996) PCR- restriction fragment length polymorphism identification and host range of single- spore isolates of the flexible Frankia sp. strain UFI 132715. Appl Environ Microbiol 62: 3026-3029

Lumini E, Bosco M, Fernandez MP (1996) PCR-RFLP and total DNA homology revealed three related genomic species among broadhost-range Frankia strains. FEMS Microbiol Ecol 21:303-311

Okito A, Alves BRJ, Urquiaga S, Boddey RM (2004) Isotopic fractionation during $\mathrm{N}_{2}$ fixation by four tropical legumes. Soil Biol and Biochem 36:1179-1190

Pawlowski K, Bogusz D, Ribeiro A, Berry AM (2011) Progress on research on actinorhizal plants. Funct Plant Biol 38:633-638.

Robinson D (2001) $\delta^{15} \mathrm{~N}$ as an integrator of the nitrogen cycle. Trends in Ecol and Evol 16:153-162.

Steele KW, Bonish PM, Daniel RM, O'Hara GW (1983) Effect of rhizobial strain and host plant on nitrogen isotopic fractionation in legumes. Plant Physiol 72:1001-1004 
Tjepkema JD, Schwintzer CR, Burris RH, Johnson GV, Silvester WB (2000) Natural abundance of ${ }^{15} \mathrm{~N}$ in actinorhizal plants and nodules. Plant Soil 219:285-289

Unkovich MJ, Pate JS (2000) An appraisal of recent field measurements of symbiotic $\mathrm{N}_{2}$ fixation by annual legumes. Field Crop Res 65:211228

Unkovich M, Pate JS, Sanford P (1993) Preparation of plant samples for high precision nitrogen ration analysis. Communications Soil Sci Plant Anal 24:2093-2106

Unkovich M, Herridge D, Peoples M, Cadisch G, Boddey RM, Giller K, Alves B, Chalk PM (2008) Measuring plant-associated nitrogen fixation in agricultural systems. ACIAR, Canberra, Australia Available from: http://aciar.gov.au/publication/mn136

Valverde C, Wall LG, Huss-Danell K (2000) Regulation of nodulation and nodule mass in relation to nitrogenase activity and nitrogen demand in Discaria trinervis (Rhamnaceae) seedlings. Symbiosis 28:49-62

Van Ghelue M, Løvaas E, Ringø E, Solheim B (1997) Early interaction between Alnus glutinosa and Frankia strain ArI3: production and specificity of root hair deformation factor(s). Physiol Plant 99:579587

Zielinska A, Nowak I (2017) Abundance of active ingredients in seabuckthorn oil. Lipids in Health and Dis 16:95. https://doi.org/10. 1186/s12944-017-0469-7

Publisher's note Springer Nature remains neutral with regard to jurisdictional claims in published maps and institutional affiliations. 